\title{
COPING WITH THE "NIMBY SYNDROME": POLITICAL ISSUES RELATED TO THE BUILDING OF BIG INFRASTRUCTURES IN LIBERAL DEMOCRACY COUNTRIES
}

\author{
Dr. Agostino MASSA, PhD \\ agostino.massa@unige.it \\ Department of Political Sciences \\ University of Genova, Italy
}

\begin{abstract}
The location and building of big hazardous infrastructures is a typical feature of the modernization process, in all countries and epochs. Since they are usually useful for a large region but their impact is very localized, the people living around the places where these facilities are active, or where their building is planned, very often organize and perform protest activities against them.

Starting from the presentation of recent data about these issues in Italy, considered as a good example of a liberal democracy country, the article is set to discuss their social and political consequences, focusing in particular on the so-called "NIMBY syndrome", its development and the strategies elaborated by public and private actors to cope with it.
\end{abstract}

Keywords: NIMBY groups, political participation, environmental protection, liberal democracy

\section{Introduction}

A typical feature of the modernization process, in every country and epoch, is the building of big infrastructures for industrial purposes, for example power 
plants, chemical factories, hazardous-waste treatment facilities, or related to the transport industry, such as railways, highways or airports. These facilities are crucial for social and economic development but present heavy externalities on the environment in terms of pollution, noise or waste disposal. While they are useful for a whole region or even for a whole country, their impact is very localized, so that only few local communities have to carry the burden for everybody. The people living around the places where these infrastructures are active, or where their building is planned, therefore, very often organize and perform protest activities against them and try to make pressure on the political decision-makers, using different actions and tools from a wide "repertoire of contention", as in the words of C. Tilly.

The aim of this article, starting from the presentation of recent data about the situation of these issues in Italy in 2017 (Blanchetti and Seminario 2018), is to discuss their social and political consequences in liberal democracy countries, focusing in particular on the so-called "NIMBY syndrome" (Mazmanian and Morell 1990), its development and the strategies elaborated by public and private actors to cope with it.

\section{Activity of NIMBY groups in Italy}

The building of big infrastructures has generally characterized the phase of economic transition from agriculture to industry in developing countries but it is still an issue today also in the more developed ones. Where the modernization process has encompassed both industrial development and a liberal democratic political system, the siting and building of hazardous facilities have often led to the rise of local protest groups, usually called "NIMBY", an acronym from the words “Not In My BackYard” (Freudenburg 1984).

The option to stand against such political decisions, on the contrary, is quite impossible in countries with a political regime different from liberal democracy. Our analysis here will be focused only on countries featuring this democratic system of government, in which multiple distinct political parties compete at elections, institutional powers are separated, individual rights and freedoms are 
officially recognized and protected, and the exercise of political power is limited by the rule of law.

Italy can be taken as a good example of a liberal democracy country where these protest activities seem to be widespread, even if within a declining trend. Among the most contested infrastructures, in our opinion, two have achieved iconic relevance because the groups standing against them have been able to raise the political debate from the local to the national stage: these are the cases of the NoTAV and the No-TAP movements.

The first are the groups that since 2005 are organizing protests, sometimes even violent, against the building of a high-speed railway ${ }^{1}, 270 \mathrm{~km}$ long, between the French city of Lyon and the city of Turin, in Northern Italy. No-TAV protest groups are against, in particular, the Italian section of the project, to be developed in the Susa Valley (see, among others: (Berta and Manghi 2006, Bettini 2006, Calafati 2006)).

The second are the groups active in more recent years in the Apulia Region, in Southern Italy, against the infrastructures necessary to the coming ashore of the Trans Adriatic Pipeline (TAP), part of a longer conduct planned to transport natural gas from the Caspian region to Europe.

According to NimbyForum, a think-tank that since 2004 is set to observe and monitor these social and political phenomena, in 2017 there were 317 infrastructures that became target of protest groups, included the two above-mentioned, about 11,7\% less than the 359 of the previous year (Blanchetti and Seminario 2018, p. 15). Among them 80 have been contested in 2017 for the first time, while their number was 119 in 2016. Such declining trend, steady along the last eight years, if on the one hand could mean a diminution in anti-industrial attitudes in Italian civil society, on the other hand can be related to lower levels of industrial investment, notably in the last phase of the recent great economic crisis.

Most targets of NIMBY groups in 2017 were infrastructures in the energy sector $(57,4 \%)$, for examples oil rigs or big power lines, others were hazardous-waste treatment plants $(36,0 \%)$ or facilities related to the transport industry $(5,7 \%)$ (Blanchetti and Seminario 2018, p. 16). 
The survey offers also data about the subjects prompting these protests. Slightly more than one third of them can be found among common citizens (34,6\%), while are important also public institutions $(26,3 \%)$ and political actors $(25,4 \%)$. It is worth stressing the lesser relevance of environmentalist associations (9,6\%) and trade unions (4,1\%) (Blanchetti and Seminario 2018, p. 20).

The picture of Italy drawn by this research is that of a country divided between two different and conflicting souls, the pro-industrialist and the NIMBY ones. What is striking is that each of them are respectively finding support in one of the two parties currently forming the national Government - rather than in opposition parties.

As for the attitudes towards the building of new infrastructures, according to the think-tank, the country is far from any form of equilibrium and harmonious matching of development and sustainability, between industrial modernisation and active citizen participation (Blanchetti and Seminario 2018, p. 24).

\section{The rise of the "NIMBY syndrome"}

Protest activities carried out in Italy are common to many industrialized countries, where since the early 1980s the presence of environment-concerned social movements increased. Target of these protests has been often the localization of big public infrastructures, potentially harmful to the environment and dangerous for citizens' health. Before that period, especially in the Usa, decisions about facility siting were set according to market rules. Private companies were free to decide when, how and where they had to be placed, considering just economic factors. There were no laws at national level to limit land exploitation and to protect the environment. Moreover, it must be added that the lack of scientific and technical information about pollution damages was an obstacle to people mobilization.

A key date in this context is 1970. As D. Mazmanian and D. Morell (1990, p. 127) have noted, that year ushered in the environmental movement as a major social and political force in the United States. The celebration of the Earth Day, the signing of the National Environmental Policy Act, the creation of the President's Council on Environmental Quality and the Environmental Protection Agency 
were followed quickly by the initiation of dramatic revisions in the laws about nation's air and water pollution. Since that, decisions about major infrastruture projects, industrial facilities and waste management have not been the same.

At the end of the 1970s, also social scientists became more interested in the study of environmental problems. Very soon they had the need to find out proper definitions for new concepts. The term NIMBY was created to describe the reaction of citizens and local communities to actual, or even potential, infrastructure or facility siting when they are supposed to be dangerous for the environment and therefore to their interest.

The acronym has got a negative meaning, as far as it is usually referred to citizen mobilizations very local and particular, often considered as driven just by selfinterest (Bobbio and Zeppetella 1999, p. 186). This is not the only acronym created in the anglosaxon literature on environmental conflicts. Widespread is also the term LULUs, from the words "Locally Unwanted Land Uses", associated to a more neutral meaning (Vecchi 1992, p. 103). Sometimes, a NIMBY attitude can even turn into BANANA, which stands for "Building Absolutely Nothing Anywhere Near Anyone" (or Anybody).

An article from the «New York Times» (June 19th, 1988) describes NIMBYs as «people who live near enough to corporate or government projects - and are upset enough about them - to work to stop, stall, or shrink them». They organize, march, sue and make petitions in order to block the developers they think are threatening them. They demonstrate an ability to use the legal and political systems to cause interminable delays and oftentimes kill a project. The specter of endless cost increase associated with such delays prompts many projects developers to retreat and inhibits many other proposals entirely (Mazmanian and Morell 1990, pp. 125-126).

NIMBY groups are usually time-bounded, they last as long as the problems stand. When they face big and long-lasting problems, they can join together and establish a permanent coordination board. In many cases studied in Italy, they are not just "No-groups" but demontrate the capacity to offer alternative proposals. The analysis and solutions to problems are technical and not political, even if these groups can have relationships with political parties and local politicians. It has been found that adults take part in NIMBY groups more often than young people. Women participate more than in traditional political parties (Massa 2005). 
They show organization models and mobilization styles very close to new styles of political participation recently identified in Italy with regard to young people's political culture: independence from traditional political parties and the political system; increase of subjective political behaviour and refusal of heterodirection; emphasis of pragmatism and issues more and more referred to everyday life specific problems (Ferrari Occhionero 1999, p. 611). These attitudes and behaviours can be considered as evidence of a "new political culture" (Beck 1992, p. 185), less depending on hierarchical organizations and more based on resources democratization (Clark and Hoffmann-Martinot 1998).

\section{Reasons behind the rise of NIMBY groups}

The setup and development of NIMBY groups have reasons that can be found at micro as well as macro social level.

In single local cases, the rise of the NIMBY syndrome has been considered as «a response to an inherent imbalance in the distribution of a project's benefits and costs. Costs in terms of human health and environmental and aesthetic decay are concentrated in one community, while benefits accrue across a much broader area and to distant corporations» (Mazmanian and Morell 1990, p. 126). Local communities can be aware of the expected benefits that the planned facility can offer to a region or even to the whole country, but they say that public authorities or companies should choose a site "Not In My BackYard"! Such answer is based on the fear of diminution of social status, slump of real estate value, increase of health or safety risks (Bobbio and Zeppetella 1999, p. 188).

Even if the rising of NIMBY groups is based locally, it can be considered as caused by the diffusion of particular values and attitudes in a broader social dimension. Local oppositions to facility siting share in fact a more general concern about environment and health damages, widely spread in contemporary "risk society".

According to U. Beck (1992, p. 21), risks can be defined «as a systematic way of dealing with hazards and insecurities induced and introduced by modernization itself». They are defined as the probabilities of physical harm due to given technological or other processes.The main feature of risks, in this approach, 
is that they are socially produced and they can have consequences on people's health and safety, directly as in the case of food manipulation or in the case of mismanagement of nuclear plants, or indirectly as in the case of the destruction of natural environment.

Risk society is different from earlier epochs. In contrast to all of them (including industrial society), it is «characterized by a lack: the impossibility of an external attribution of hazards. In other words, risks depend on decisions, they are industrially produced and in this sense politically reflexive» (Beck 1992, p. 21). In such a society, «the sources of danger are no longer ignorance but knowledge; not a deficient but a perfected mastery over nature» (Beck 1992, p. 183). This is the case, of course also of environmental problems. As it has been stressed, «The modern paradox is that the industrial system that spawns America's material affluence is simultaneously the source of enormous pollution load for the air, water and land» (Mazmanian and Morell 1990, p. 127).

People are exposed to information about risks from the media system and so their level of concern rises. Therefore, when they find at local level a situation reflecting a global concern, they can become fearful and organize a protest group against the potential danger. They feel as they are participating into a commonality of anxiety, which has taken the place of the commonality of needs. In Beck's perspective, the place of the value system of the "unequal" society is taken by the value system of the "unsafe" society. While in the former people's needs could have been summarized in the claim "I am hungry!", in the latter the claim is "I am afraid!" (Beck 1992, p. 49).

Another important reason for the development of NIMBY groups lies in the fall of confidence in the effectiveness of public institutions, at central and locallevel. In the last quarter of the 20th century, the crisis of the State and its governing functions has become evident, made then even more severe by the effects of globalization processes $^{2}$. In a local dimension, political institutions in charge of governing the territory are asked to make difficult decisions about the urban design of cities, the siting of hazardous facilities, the protection of the environment. Different are the actors involved in the decision process and different, often conflicting, are

2 For a summary of the debate on this topic, for instance, see: Held and Mc Grew (2003, pp. 121-125). 
their interests. As long as «the public's confidence in business and government leaders to make well-informed, impartial, safe and prudent decisions has severely diminished» (Mazmanian and Morell 1990, p. 127), there is room for citizens to mobilize. Fearing that decisions from public authorities could be against their interests and losing hope in their representatives in elected political instituions, they set up protest groups to delay or to block the decision process.

In the frame of Beck's theory, NIMBY groups can be considered part of what he defines as "sub-politics". They bring out new demands for political participation outside the political system in the form of a new political culture. As the German author argues, "The impression of "political" standoff is deceptive. It arises only because the political is limited to what is labeled political, to the activities of the political system. If one conceives it more broadly, then one sees that society is caught in a whirlpool of change that richly deserves the title "revolutionary" - quite apart from how one evaluates it. This social transformation, however, occurs in the form of the non-political. In this sense the discontent with politics not only is the discontent with politics itself, but results from the disproportion between an authority to act which plays political and is becoming powerless, and a broad-scale change of society, closed off to social decision-making, that approaches unstoppably but quietly in the guise of the nonpolitical. Correspondingly, the concepts of the political and the non political become blurred and require a systematic revision» (Beck 1992, p. 185).

\section{Possible answers to NIMBY group requests}

The traditional approach to manage conflicts about facility siting is called "DecideAnnounce-Defend". It means that after the decision of placing a factory or an infrastructure in one place, the public institution or the private company announce it to the local community. Then they defend this decision against protests, if any.

This rigid approach is not working anymore. The siting of useful but unwanted infrastructures, without the approval of local communities, is more and more difficult. Such approval can be achieved only including local communities into the decision making process. Nevertheless it is still possible to count many cases in which local administrations adopt rigid and not effective "Decide-Announce- 
Defend" strategies, even if technical aspects of the programmes are rediscussed and more information is given to the citizens.

There are many alternative approaches to overcome the conflict among facility proposers and local communities.

The first one is the "privatization model", according to which siting decisions are let to market rules. It includes the privatization of public land and a quicker solution of possible controversies by way of appealing to ordinary judge. Considering land a private property, citizens could sue those responsible for damages and ask for compensation. The weak point of this approch is that it can be applied just to situations in which there are existing damages and thet it pays very little attention to prevention activities (Vecchi 1992, p. 110).

A second strategy is the creation of a "localization contract" among facility managers and local communities, as proposed by M.L. Poirier Elliott (1984). Evidence from different studies shows that those who live close to potentially dangerous infrastructures are the most interested into the effectiveness of prevention systems and to fix possible failures. On this basis, long term agreements are set to let members of the local community get involved in the siting decision making process and then into monitoring activities. Also in this case it will be possible to take ordinary legal proceedings and allow citizens to have a better protection. This approach can be understood in the tradition of civic engagement and participation typical of the USA, giving to organized groups actual power. The feature more envied by European observers, used to deal with impenetrable bureaucracies, is the opportunity given to organize groups to get a very active role into the decision making process.

In the more general frame of the change in attitudes towards environmental issues typical of the "70s in the USA as well as in the most industrialized countries, as described in the previous paragraphs, scientists interested in the social and legal aspects of environment protection got to the definition of new approaches for the resolution of social conflicts, using negotiation techniques instead of legal proceedings. Their opinion was that such methods did not pay due attention to the "natural" development of social conflicts, reducing them just to their legal dimension, finding out ways for compensation but not for their actual solution (Salanitro 1991). 
In different areas of the USA conflicts were solved through negotiation and mediation, based on the participation and cooperation of all stakeholders to the decision and implementation of environmental policies.

The first important case in which mediation has been successful was the building of a dam on the river Snoqualmie, close to Seattle, to keep periodical floods under control. The controversy began in 1959 and was considered with no way out. A negotiation process started in 1974 and under the guidance of an indipendent "mediator" the two quarrelling parties got to an agreement: the dam was to be built but in another site and in the frame of a land using programme more respectful of the environment. After this first successful case, the utilization of the negotiation method increased dramatically and many private agencies became specialized in this kind of business.

A similar approach to solve conflicts about facility siting has been developed by L. Susskind. The social scientist and his researching team at the Massachusets Institute of Technology studied more than 1800 cases of environmental conflicts and elaborated a method for their solution (Susskind and Cruikshank 1987). This technique is based on the role of the "facilitator" who has the task to take the two parties to an agreement. At the very beginning the facilitator meets the parties to convince them to take part in the cooperation process. After the achievement of this preliminary point, the parties must designate their representatives for the negotiation, defining their responsibilities and functions. The facilitator then sets the rules of the process and gives the parties all the information available about facility siting. The publicity of information is the key factor of this method. On this basis, the facilitator and the parties work together to find out alternative solutions and a final outcomes acceptable for all. At the end of the negotiation process the agreement is undersigned in a formal act (Vecchi 1992).

According to Susskind, one good point of this approach regards the fairness of results. When all the actors interested in an agreement are actively involved in the decision making process, it is possible that benefits and losses related to the building of the facility are fairly shared among them. Another good point is the efficiency of the approach, because it guarantees shorter times and lower costs for the facility development. Local opposition can delay or even stop quite every projects of this kind. Moreover, the NIMBY syndrome is contagious and when a protest group is successful, its behaviour can be imitated by others. To get both 
points - efficiency and fairness - a complex negotiation process is needed, in which the approval by local communities is achieved on the basis of full access to information. A last good point is the stability of results that this approach can offer, because both parties get incentives to make the agreement working.

These cases show that a process based on negotiation, in which all stakeholders are fairly represesented, is more effective than the traditional ones (Bartolomeo 1996, pp. 48). A balanced agreement among different interests is considered as the best solution to prevent discontent and preserve social cohesion. This method, however, has been criticized by other American social scientists. According to the negotiation approach, environmental conflicts rise just because of misunderstanding among different parties and can be solved after an accurate analysis of their positions. The situation can be actually more complicated. When one of the disputing parties is an environmental protest group, the negotiation process becomes quite impossible.

In last decades, the number of protest groups concerned about environment protection has increased worldwide. The mobilization does not interest just those people living close endangered areas or afraid of a facility siting, but is connected with a general ideology and social values. It happens therefore that in environmental conflicts such groups fight for the affirmation of these values more than claiming for damages compensation. That is why, in these specific cases, the negotiation approach suggested by Susskind does not work. When the matter is about basic values, a balanced agreement cannot be accepted.

Last but not least, the "compensation method" is another interesting political instrument used to deal with conflicts and to get to a fair and efficient agreement about facility siting. In the perspective adopted by some authors to study different cases in the USA (Himmelberger et al. 1991), local opposition can be overcome offering incentive to the residents of the area interested by the siting of an unwanted infrastructure. This can be developed as soon as the costs-benefits analysis for members of opposition groups turns from negative into positive.

V. Amato (1996) shows how the level of compensation can be affected by the characteristics of the proposed infrastructure and by the social and economic conditions of the interested area. In general terms, the localization of public facilities is considered as related to a level of compensation higher than private 
ones, because public administrations, for political reasons, are keener on looking for voters' approval. With regard to the purpose of the new facilities, when they are going to deliver services to a large area it is possible to claim for a compensation higher than in the case of a smaller one. Local communities making only little use of the services provided by the new facility will get a higher compensation as well.

The relation among the level of compensation and the social and economic characteristics of the area is also important. In general terms, working-class districts with poor education level and low individual income get usually a lower compensation. People with such social and economic status find very difficult to stand up successfully for their claims and rights. They are not likely to be close to political power and neither able to set up effective pressure groups, so that the compensation they get is not always fair.

Nevertheless, it is the effectiveness of the method itself to be often criticized, as it is difficult in fact to decide the exact amount of money for compensation. Many proposals have been offered to this purpose. Some argue that the amount of compensation should be decided only at the end of negotiations about the safety of the infrastructure. Others maintain that the decision could be made just according to market rules. Finally, a fairer solution could be achieved if compensations are not negotiated directly by the two quarrelling parties but by all the communities of the area set to receive the facility, before the decision about its actual siting. Another relevant question regards the choice of the kind of compensation. This can be given in terms of money, employment or other benefits for the community: for instance, sport facilities or housing programmes for disadvantaged people.

\section{Conclusions}

Drawing from the scientific literature on the topic as well as from the experience of Italy, as an example of a liberal democracy, some final considerations, useful also in a wider perspective, can be outlined about:

- the decision process made by public authorities to locate and build big infrastructures with relevant consequences for local environment;

- the relationships between NIMBY groups and political parties and institutions; 
- the dealing of public authorities with the rise and development of protest groups and their activities against big infrastructures.

In the decision process about the location of these infrastructures and its implementation, made by political actors legitimized by a democratic election, it has to be stressed, first of all, the importance of communication.

It is crucial the need to involve local communities in the process from the very first start, to meet and talk to them. Information activities must be carried out in order to try to win their support, focusing on the positive aspects of the projects, considering also forms of compensation. It must be found anyway a fair balance between collective interest and local concerns.

Communication aspects are important also the other way round. Within local communities there are often different attitudes about such projects, some in favour and some contrary. Prevailing voices are usually the most able to get their message going towards the wider public opinion and political decision-makers, even if this does not mean that they are always the most representative of real local attitudes.

A second set of remarks deals with the relationships between NIMBY protest groups and political actors. Such groups may decide to offer electoral support to some political parties, in order to achieve their goals to stop the development of industrial projects they consider dangerous or anyway with a hard impact on their local environment. To "ride" local protest and to get on with these groups, is (relatively) easy for political parties when they are part of the opposition, at local or at national level. When they succeed to get to government positions, however, they can decide either to pay for their electoral obligations and cancel these projects or to change their mind and let them go on. The second option is very frequent, since once they hold institutional positions, political actors have to look at these issues from a wider point of view, considering also aspects of national interest and not just local concern. When political parties in government positions decide not to fulfil the promises made during the electoral campaign, the outcome can be either a harsher conflict between local communities and political decision-makers or an increased mistrust in politics and political actors.

The situation can be even more complicated when there are different attitudes about these issues between political forces holding power positions in local or 
regional authorities and those supporting the national Government - both of them legally elected in a democratic process.

A third set of considerations, finally, regards how public authorities have to deal with the rise and development of protest groups and their pressure activities.

Even if demonstrations can get a very confrontational character, it is important to grant a fair balance between the roles of all the different actors taking part in the process: the national Government, Parliament, but also local government authorities, the Judiciary and the police, political parties and independent local pressure groups.

Very often protest movements have a broad constituency. They may include, among others: associations, economic actors, political groups, citizens committees and families. Even in the age of globalization, there are many who cannot or simply do not want to move from one place that is likely either to become or to be perceived as dangerous or uncomfortable, choosing "exit", so that protest, i.e. "voice" (Hirshmann 1970), is the only option they have.

Another problem is therefore that when a protest event is organized, for example, a sit-in, a rally or a flash-mob, a violent fringe of very few may come out of a pacific huge crowd. This is particularly likely to happen when a protest event is taken as a pretext for wider political actions on a larger scale, with activists coming from outside to join local groups. Nonetheless, nobody's rights should be ever denied, in liberal democracies. It is an uneasy but necessary task for public authorities to let pacific people enjoy their civil rights and carry on their strong but pacific protest, always within a legal frame, and to prevent violent people from making damages to either persons or things - destroying at last democracy itself.

\section{References}

Amato, V., 1996. Sindrome Nimby, che fare?. Gea, March-April, pp. 8-11.

Bartolomeo, M., 1996. Porte aperte a chi rema contro: far pace negoziando. Impresa Ambiente, 3, pp. 44-49.

Beck, U., 1992. Risk Society. Towards a New Modernity. Sage Publications, London Thousand Oaks - New Dehli.

Berta, G., Manghi, B., 2006. Una Tav per partito preso. Il Mulino, n. 423, pp. 92-101. 
Bettini, V., 2006. Tav: i perché del no. Utet, Turin.

Blanchetti, E., Seminario, S. (eds), 2018. L'Era del Dissenso. Osservatorio Nimby Forum, $13^{\wedge}$ ed. 2017/2018. [online]. Available from: http://www.nimbyforum.it [Accessed 14 Dec 2018]

Bobbio, L., Zeppetella, A. (eds), 1999. Perché proprio qui? Grandi opere e opposizioni locali. FrancoAngeli, Milan.

Calafati, A.G., 2006. Dove sono le ragioni del sì? La Tav in Val di Susa nella società della conoscenza. Seb27, Turin.

Clark, T.N., Hoffmann-Martinot, V. (eds), 1998. The New Political Culture. Westview Press, Boulder - Oxford.

Ferrari Occhionero, M., 1999. L'ethos della disaffezione negli atteggiamenti politici dei giovani. In Bettin, G. (ed), Giovani e democrazia in Europa. CEDAM, Padua.

Freudenburg, W.R., 1984. Not in our backyards! Community action for health and environment. Monthly Review Press, New York.

Held, D., McGrew, A., 2003. Political Power and Civil Society: A Reconfiguration?. In Held, D., McGrew, A. (eds), The Global Transformations Reader. An Introduction to the Globalization Debate. Polity Press, Cambridge.

Himmelberger, J.J., Ratick, S.J,. White, A.L., 1991. Compensation for Risks: Host Community Benefits in Siting Locally Unwanted Facilities. Environmental Management, (5)15, pp. 647-658.

Hirschmann, A.O., 1970. Exit, Voice, and Loyalty. Harvard Univ. Press, Cambridge (MA.) Massa, A., 2005. Partecipazione politica e governo locale a Genova. FrancoAngeli, Milan.

Mazmanian, D., Morell, D., 1990. "The "Nimby" Syndrome: Facility Siting and the Failure of Democratic Discourse". In Vig, N.J., Kraft, M.E. (eds), Environmental Policy in the 1990s. CQ Press, Washington.

Poirier Elliott, M.L., 1984. Improving Community Acceptance of Hazardous Waste Facilities Through Alternative Systems of Mitigating and Managing Risk. Hazardous Waste, 1, pp. 397-410.

Salanitro, U., 1991. L'Environmental mediation negli USA: uno strumento alternativo per la risoluzione dei conflitti ambientali?. Rivista giuridica dell'ambiente, 2, pp. 229-275.

Susskind, L., Cruikshank, J., 1987. Breaking the impasse. Consensual approaches to resolving public disputes. Basic Books, New York.

Vecchi, G., 1992. Superare il rifiuto. Conflitti ambientali e capacità decisionale: esperienze straniere di management dei processi di localizzazione di infrastrutture "socialmente indesiderate". Il nuovo governo locale, 2, pp. 103-127. 